\title{
Estimates for the semigroup associated with Bernstein-Schnabl operators
}

IOAN RAŞA

\section{ABSTRACT.}

We consider a differential operator of the form $A u(x)=\alpha(x) u$ " $(x), 0 \leq x \leq 1$. Under suitable assumptions, it generates a semigroup $(T(t))_{t} \geq 0$ which can be approximated by iterates of the Bernstein-Schnabl operators. We obtain quantitative results concerning the behaviour of $T(t)$ when $t \rightarrow 0^{+}$and $t \rightarrow+\infty$.

DePARTMENT OF MATHEMATics

TECHNICAL UNIVERSITY OF CLUJ-NAPOCA

C. DAicoviciu 15, 400020 Cluj-Napoca, Romania

E-mail address: ioan.rasa@math.utcluj.ro 